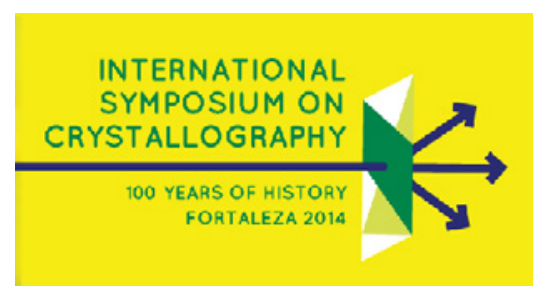

\title{
EARLY DAYS OF X-RAY DIFFRACTION - THE DISCOVERY AND THE FIRST APPLICATIONS
}

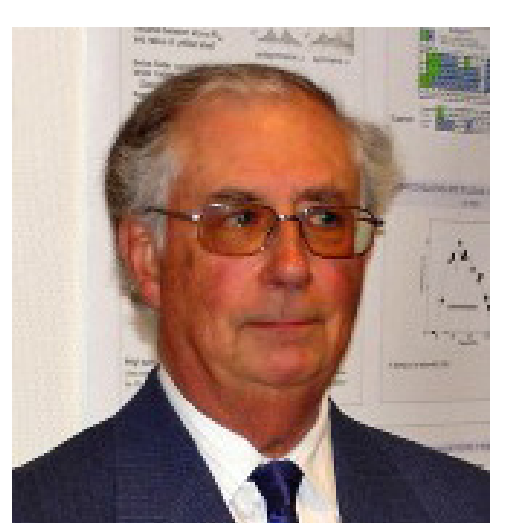

\author{
André Authier \\ Institut de Minéralogie, de Physique des Matériaux et de Cosmochimie, Université P. et M. Curie
}

The first X-ray diffraction pattern obtained by W. Friedrich, P. Knipping and M. Laue in April 1912 marked the beginning of an entirely new field of research, X-ray diffraction. It proved at the same time the wave nature of X-rays and the reality of the concept of crystal space lattices. It will be shown briefly how the concept of space lattice emerged and how it became more and more precise in the course of the nineteenth century. The funding experiment by F., K. and L. was the result of an intuition of M. Laue's following a discussion with P. P. Ewald on the latter's thesis. The topic of that thesis was the propagation of light in a regular anisotropic arrangement of dipoles. As soon as Ewald heard about the F. K. L. experiment, he realized that his theory applied to the X-ray case led to the concept of reciprocal lattice. Lawrence Bragg, in November 1912, showed that Laue's experiment could be interpreted as the diffraction of X-ray waves by a stack of lattice planes and derived Bragg's law of diffraction. The talk will tell how the first crystal structure determinations were made by Lawrence Bragg and his father and how the major techniques such as rotating crystal and powder diffraction were developed. The first applications of X-ray diffraction in the fields of chemistry, mineralogy, material science, biology and physics will then be described. 